\title{
ESTUDO DAS PROPRIEDADES MECÂNICAS DA REGIÃO SOLDADA POR ELETRODO REVESTIDO DO AÇO FUNDIDO G17CrMoV5-10 ANTES E APÓS ALÍVIO DE TENSÕES
}

\author{
STUDY OF THE MECHANICAL PROPERTIES OF THE REGION WELDED BY \\ COATED ELECTRODE OF THE CAST STEEL G17CrMoV5-10 BEFORE AND AFTER \\ RELIEF OF TENSIONS
}

\author{
Péricles Bosquetti ${ }^{\mathrm{I}}$ \\ Luis Fernando Castro II \\ Sidnei Davi Souza ${ }^{\text {III }}$ \\ Otávio Contart Gamboni ${ }^{\mathrm{IV}}$ \\ Diógenes Bosquetti ${ }^{\mathrm{V}}$
}

\begin{abstract}
RESUMO
Este trabalho teve por objetivo estudar o comportamento das propriedades mecânicas do aço fundido G17CrMoV5-10 quando submetido ao processo de soldagem com e sem o tratamento de Alívio de Tensões. Para esse estudo, foram realizados ensaios mecânicos de tração, impacto e microdureza, para avaliação de suas propriedades que foram comparadas e analisadas. Como conclusão deste trabalho foi possível afirmar que é imprescindível a aplicação do tratamento térmico de alívio de tensões após a soldagem do aço G17CrMoV510 , visto que as propriedades e modificações favoráveis que trouxeram ao material após sua realização.
\end{abstract}

Palavras-chave: Alívio de Tensões. Aço Fundido G17CrMoV5-10. Tratamentos térmicos.

\begin{abstract}
This work aims to study the behavior of the mechanical properties of the molten steel G17CrMoV5-10 when subjected to the welding process with and without the stress relief treatment. For this study will be carried out mechanical tests of traction and hardness, to evaluate their properties that will be compared and analyzed. As conclusion of this work it was possible to affirm that it is essential to apply the heat treatment of stress relief after the welding of G17CrMoV5-10 steel, considering the properties and favorable modifications that they have brought to the material after its accomplishment
\end{abstract}

Keywords: Stress relief treatment. G17CrMoV5-10 cast steel. Heat treatments.

I Prof. Dr. da Faculdade de Tecnologia (FATEC) de Sertãozinho - São Paulo - Brasil. E-mail: pericles.bosquetti@fatec.sp.gov.br

II Tecnólogo em Mecânica: processos de Soldagem pela da Faculdade de Tecnologia (FATEC) de Sertãozinho São Paulo - Brasil. E-mail: santanna.castro@gmail.com

III Tecnólogo em Mecânica: processos de Soldagem pela da Faculdade de Tecnologia (FATEC) de Sertãozinho São Paulo - Brasil. E-mail: sidnei.sds18@gmail.com

IV Prof. Dr. da Faculdade de Tecnologia (FATEC) de Sertãozinho - São Paulo - Brasil. E-mail: otavio.gamboni@gmail.com

v Prof. Pós-Dr. da Faculdade de Tecnologia (FATEC) de Sertãozinho - São Paulo - Brasil. E-mail: diogenes.bosquetti@fatec.sp.gov.br 


\section{(11)}

Data de submissão do artigo: 15/09/2019

Data de aprovação do artigo: 19/09/2019.

DOI:

\section{INTRODUÇÃO}

Um dos processos mais utilizados atualmente para melhorar as características mecânicas dos materiais são os tratamentos térmicos, os quais são definidos como um conjunto de operações de aquecimento e resfriamentos controlados, que têm por objetivo modificar as propriedades dos materiais como os aços. A evolução dos processos de tratamentos térmicos atingiu um ponto em que atualmente existem diversos tipos e são escolhidos, conforme o tipo de material e quais as propriedades se desejam a partir deles.

Neste trabalho, o objetivo é avaliar corpos de prova do aço fundido G17CrMoV5-10, submetido ao processo de soldagem por eletrodo revestido e posteriormente realizado um alívio de tensões, comparando-se as propriedades de um outro corpo de prova em que esse tratamento térmico não foi aplicado.

Como as propriedades mecânicas dos aços dependem não só de sua composição química, mas também da sua microestrutura e, considerando-se que os tratamentos térmicos possuem a capacidade de modificá-las, este estudo tem o objetivo de mostrar a influência do tratamento térmico de alívio de tensões para avaliar as modificações, tendo em vista que as propriedades mecânicas desejadas são fundamentais para os cálculos de engenharia.

\section{CLASSIFICAÇÃO DOS AÇOS FUNDIDOS CONFORME NORMA DIN EN 10213}

A classificação dos vários aços-carbono e aços-liga, quanto a sua composição química, foi estabelecida pela norma Deutsches Institut für Normung (DIN) para padronizar e limitar o grande número de composições químicas dos aços.

A Tabela 1 informa os valores de composição química do aço G17CrMoV5-10 que foi utilizado para os estudos sobre a influência do Alívio de Tensões.

Tabela 1 - Composição química nominal do aço G17CrMoV5-10

\begin{tabular}{c|c|c|c|c|c|c|c|c|c|c|c}
\hline $\begin{array}{c}\text { DIN } \\
10213\end{array}$ & $\mathbf{C}(\boldsymbol{\%})$ & $\begin{array}{c}\text { Si } \\
(\boldsymbol{\%})\end{array}$ & $\begin{array}{c}\mathbf{M n} \\
(\boldsymbol{\%})\end{array}$ & $\begin{array}{c}\mathbf{P} \\
(\boldsymbol{\%})\end{array}$ & $\begin{array}{c}\text { S } \\
(\boldsymbol{\%})\end{array}$ & $\begin{array}{c}\mathbf{C r} \\
(\boldsymbol{\%})\end{array}$ & $\begin{array}{c}\text { Mo } \\
(\boldsymbol{\%})\end{array}$ & $\begin{array}{c}\mathbf{N i} \\
(\boldsymbol{\%})\end{array}$ & $\begin{array}{c}\mathbf{C u} \\
(\boldsymbol{\%})\end{array}$ & $\begin{array}{c}\text { Sn } \\
(\boldsymbol{\%})\end{array}$ & $\begin{array}{c}\text { V } \\
(\boldsymbol{\%})\end{array}$ \\
\hline Mínimo & 0,150 & 0,400 & 0,500 & - & - & 1,200 & 0,900 & - & - & - & 0,200 \\
\hline Máximo & 0,200 & 0,600 & 0,900 & 0,020 & 0,015 & 1,500 & 1,100 & 0,400 & 0,300 & 0,025 & 0,300 \\
\hline
\end{tabular}

Fonte: Certificado 23175 da Fundição USIMONTEC (2017)

Algumas das propriedades mecânicas, tais como: resistência à tração, limite de escoamento e resistência ao impacto do aço G17CrMoV5-10 utilizado neste trabalho, estão classificadas de acordo com a Tabela 2. 


\section{(11)}

Tabela 2 - Propriedades mecânicas do aço G17CrMoV5-10

\begin{tabular}{l|c|c|c|c}
\hline DIN 10213 & $\begin{array}{c}\text { Limite de } \\
\text { Resistência } \\
\text { (MPa) }\end{array}$ & $\begin{array}{c}\text { Limite de } \\
\text { Escoamento } \\
(\mathbf{M P a})\end{array}$ & $\begin{array}{c}\text { Alongamento } \\
\mathbf{( \% )}\end{array}$ & $\begin{array}{c}\text { Resistência ao } \\
\text { Impacto 20 } \mathbf{C}(\mathbf{J})\end{array}$ \\
\hline Mínimo & 590 & 440 & 15 & 27 \\
\hline Máximo & 780 & - & - & - \\
\hline
\end{tabular}

Fonte: Certificado 23175 da Fundição USIMONTEC (2017)

\subsection{Aço G17CrMoV5-10}

O aço G17CrMoV5-10 é um material classificado na norma DIN EN 10213 com o número 1.7706, este material faz parte de um grupo denominado $\mathrm{CrMoV}$, de acordo com o catálogo Technical Handbook, Metrode Welding Consumables, é um aço resistente ao calor e à corrosão ao mesmo tempo, a variante de resistência mais evidente do material é a resistência ao desgaste. Os materiais a base $\mathrm{CrMoV}$ proporcionam boa resistência a ruptura por fluência até cerca de $580^{\circ} \mathrm{C}$, com um grau razoável de resistência à corrosão em vapor superaquecido. Aplicações típicas para os materiais fundidos incluem carcaças de válvulas, turbinas a vapor, uso geral para caldeiras, vasos de pressão na geração de energia e indústrias petroquímicas (METRODE WELDINGS CONSUMABLES, 2016).

\subsection{Tratamentos Térmicos}

Um tratamento térmico é definido como uma combinação de operações de aquecimento e resfriamento aplicado a metais e ligas em estado sólido para obter certas características ou propriedades desejadas. Os tratamentos térmicos têm a finalidade de modificar a microestrutura dos materiais e, consequentemente, suas propriedades mecânicas, as quais estão intimamente relacionadas com a microestrutura (CHIAVERINI, 2012). Um dos tratamentos utilizados para melhorar a ductilidade de um material é o Alívio de Tensões, que foi utilizado neste trabalho.

\subsection{Tratamento Térmico de Alívio de Tensões}

Alívio de tensões consiste no aquecimento do aço a temperaturas abaixo do limite inferior à da zona crítica (CHIAVERINI, 2012).

Este tratamento térmico tem a finalidade de melhorar as características mecânicas dos materiais através de um aquecimento controlado com temperaturas de subida na ordem de 40 a $150^{\circ} \mathrm{C}$ por hora, normalmente abaixo da temperatura crítica de transformação, para que as propriedades mecânicas como tensão de alongamento e ruptura fiquem estabelecidas entre um limite mínimo aceitável, permanecendo por um período de tempo, normalmente proporcional a espessura das peças, seguido de um resfriamento lento na mesma grandeza da temperatura de subida. Através desse processo, é possível aliviar as tensões resultantes dos processos de fundição, conformação mecânica e soldagem, além de homogeneizar o tamanho dos grãos, regularizarem a textura de fusão e melhorar a usinabilidade. Essas propriedades irão variar de acordo com a temperatura de aquecimento (MARQUES; MODENESI; BRACARENSE, 2016). 


\section{(10i1)}

Não devemos confundir a operação de alívio de tensões com tratamentos de recozimento, onde as temperaturas são bem mais elevadas, acima da temperatura crítica de transformação do material, mas que também reduzem as tensões internas.

$\mathrm{Na}$ maioria dos metais, o tratamento de alívio de tensões não modifica as características microestruturais, não substituindo outros tratamentos específicos com essa finalidade, porém ocorre um aumento considerável no tamanho dos grãos e que se os parâmetros de aquecimento, patamar e resfriamento não forem devidamente controlados, pode acarretar em defeitos nas discordâncias do material aumentando a sua fragilidade que por consequência diminuirá suas propriedades mecânicas, como dureza e resistência a tração (GARCIA, 2011).

\section{PROCEDIMENTOS METODOLÓGICOS: material utilizado para soldagem dos Corpos de Prova}

Para realização deste trabalho utilizaram-se corpos de prova em aço carbono martensítico G17CrMoV5-10 conforme norma DIN EN 10213 que foram retirados de quatro placas fundidas nas dimensões de 200 x 150 x 50mm conforme mostrado na Tabela 3 feita a partir do certificado de qualidade mostrado no anexo A.

Tabela 3 - Placa de aço fundido G17CrMoV5-10 conforme DIN EN 10213

\begin{tabular}{c|c|c|c|c|c|c|c|c|c|c}
\hline & $\mathbf{C}(\boldsymbol{\%})$ & $\begin{array}{c}\text { Si } \\
(\boldsymbol{\%})\end{array}$ & $\begin{array}{c}\mathbf{M n} \\
(\boldsymbol{\%})\end{array}$ & $\begin{array}{c}\mathbf{P} \\
(\boldsymbol{\%})\end{array}$ & $\begin{array}{c}\mathbf{S} \\
(\boldsymbol{\%})\end{array}$ & $\begin{array}{c}\mathbf{C r} \\
(\boldsymbol{\%})\end{array}$ & $\begin{array}{c}\text { Mo } \\
(\boldsymbol{\%})\end{array}$ & $\mathbf{N i}(\boldsymbol{\%})$ & $\begin{array}{c}\mathbf{C u} \\
(\boldsymbol{\%})\end{array}$ & $\begin{array}{c}\text { Sn } \\
(\boldsymbol{\%})\end{array}$ \\
\hline Mín & 0,150 & 0,400 & 0,500 & 0,000 & 0,000 & 1,200 & 0,900 & 0,000 & 0,000 & 0,000 \\
\hline Obtido & $\mathbf{0 , 1 9 9}$ & $\mathbf{0 , 4 6 8}$ & $\mathbf{0 , 6 1 7}$ & $\mathbf{0 , 0 2 0}$ & $\mathbf{0 , 0 1 0}$ & $\mathbf{1 , 3 2 0}$ & $\mathbf{0 , 9 6 6}$ & $\mathbf{0 , 3 9 8}$ & $\mathbf{0 , 0 2 5}$ & $\mathbf{0 , 0 0 1}$ \\
\hline Máx & 0,200 & 0,500 & 0,900 & 0,020 & 0,015 & 1,500 & 1,100 & 0,400 & 0,300 & 0,025 \\
\hline
\end{tabular}

Fonte: Certificado 23175 da Fundição USIMONTEC (2017).

\subsection{Metal de Adição}

Para soldagem das placas foi utilizado o Eletrodo Revestido básico de baixo hidrogênio E9018-B3 Ø5mm que é composto basicamente por 2,25\%Cr e $1 \%$ Mo de acordo com informações de composição química do fabricante WELDINOX conforme Tabela 4.

Tabela 4 - Composição Química do Eletrodo E9018-B3 fabricante WELDINOX

\begin{tabular}{c|c|c|c|c|c|c|c}
\hline ASME II, PART C & $\mathbf{C}(\boldsymbol{\%})$ & $\mathbf{S i}(\boldsymbol{\%})$ & $\mathbf{M n}(\boldsymbol{\%})$ & $\mathbf{P}(\boldsymbol{\%})$ & $\mathbf{S}(\boldsymbol{\%})$ & $\mathbf{C r}(\boldsymbol{\%})$ & $\mathbf{M o}(\boldsymbol{\%})$ \\
\hline Mínimo & 0,050 & - & - & - & - & 2,000 & 0,900 \\
\hline Encontrado & $\mathbf{0 , 0 8 1}$ & $\mathbf{0 , 1 6 7}$ & $\mathbf{0 , 3 8 8}$ & $\mathbf{0 , 0 2 5}$ & $\mathbf{0 , 0 2 0}$ & $\mathbf{2 , 1 4 0}$ & $\mathbf{0 , 9 8 5}$ \\
\hline Máximo & 0,120 & 0,800 & 0,900 & 0,020 & 0,030 & 2,500 & 1,200 \\
\hline
\end{tabular}

Fonte: Certificado 23466 da WELDINOX (2017)

\subsection{Parâmetros de Soldagem}

Após o processo de montagem, foram selecionados os parâmetros de Soldagem e executados conforme as condições apresentadas na Tabela 5, para cada um dos parâmetros: pré-aquecimento, consumível de soldagem, interpasse, corrente, tensão, velocidade e tratamento térmico pós-soldagem. 


\section{(11)}

Tabela 5 - Parâmetros Utilizados no Processo de Soldagem utilizado

\begin{tabular}{c|c|c|c|c|c|c}
\hline $\begin{array}{c}\text { Consumível } \\
\text { Ø5018-B3m }\end{array}$ & $\begin{array}{c}\text { pré- } \\
\text { aqueciment } \\
\mathbf{0}\left({ }^{\circ} \mathbf{C}\right)\end{array}$ & $\begin{array}{c}\text { Interpass } \\
\mathbf{e}\left({ }^{\circ} \mathbf{C}\right)\end{array}$ & $\begin{array}{c}\text { Tensão } \\
(\mathbf{V})\end{array}$ & $\begin{array}{c}\text { Corrent } \\
\mathbf{e}(\mathbf{A})\end{array}$ & $\begin{array}{c}\text { Velocidade } \\
(\mathbf{c m} / \mathbf{m i n})\end{array}$ & $\begin{array}{c}\text { Temperatura } \\
\text { de Trat. } \\
\text { Térmico }\left({ }^{\circ} \mathbf{C}\right)\end{array}$ \\
\hline Mínimo & 200 & - & 25 & 180 & 15 & 680 \\
\hline Máximo & 300 & 400 & 30 & 240 & 25 & 700 \\
\hline
\end{tabular}

Fonte: os autores (2019)

\subsection{Tratamentos Térmicos}

Foi realizado o Tratamento Térmico de Alívio de Tensões na temperatura de $680^{\circ} \mathrm{C}$, permanecendo por duas horas em patamar. Os ciclos de subida e descida de temperatura foram realizados à uma razão de $80^{\circ} \mathrm{C}$ por hora

\subsection{Preparação das Amostras}

Os corpos de provas foram usinados numa fresadora universal para uniformizar a espessura deixando-os nas dimensões de comprimento mínimo de $150 \mathrm{~mm}$, largura de 200 mm e espessura de $40 \mathrm{~mm}$ conforme indicado na norma ASME IX, 2008, executado os biséis para soldagem e montando-os conforme mostra a Foto 1. A chapa foi soldada na posição horizontal plana ( $2 \mathrm{G})$ utilizando uma máquina de solda Inversora, pelo processo de Eletrodo Revestido, sendo utilizado um maçarico para pré-aquecimento e lápis térmico para controle da temperatura, conforme Foto 2.

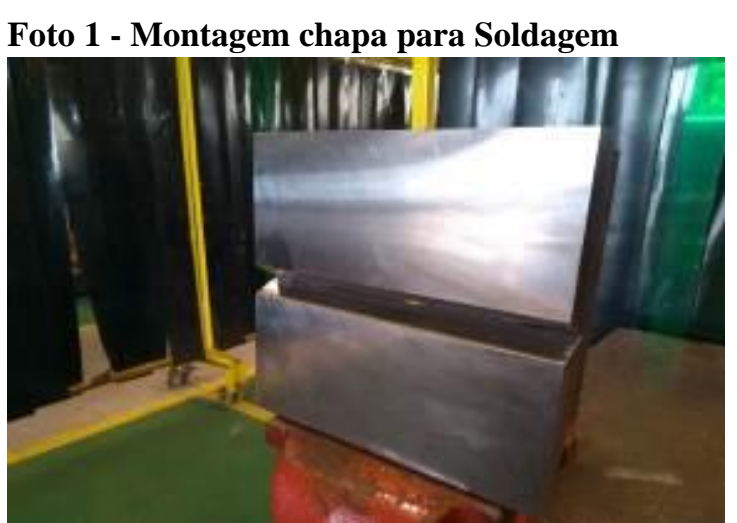

Fonte: os autores (2019)
Foto 2 - Soldagem dos corpos de prova

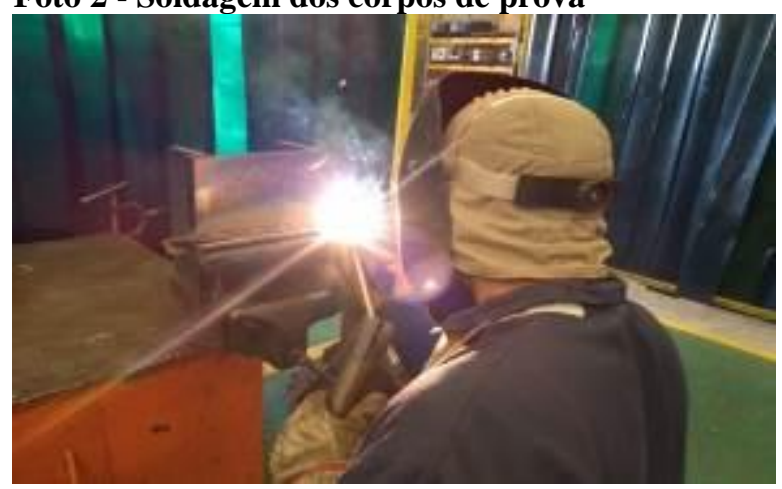

Fonte: os autores (2019)

\subsection{Análises por microdureza Vickers e Macrografia da região soldada}

Foram preparadas duas amostras para execução do ensaio de microdureza pelo processo de fresamento e posterior sequência de lixamentos com lixas d'água de granulações até 2000, polimento para melhor visualização da solda e posterior ataque com reagente Nital a $3 \%$. A amostra identificada como CP 01 não foi submetida ao processo de Tratamento Térmico de Alívio de Tensões, enquanto a amostra denominada CP 02 foi submetida ao referido processo. A Figura 1 mostra a macrografia (ataque Notal 3\%) da superfície preparada para execução do Ensaio de Dureza Vickers e os pontos para medição de microdureza realizados, estão representados esquematicamente na Figura 2. 


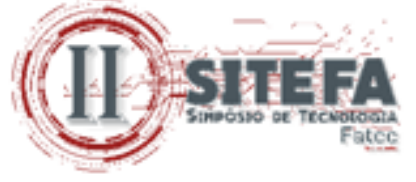

Figura 1 - Macrografia da Solda (Nital 3\%)

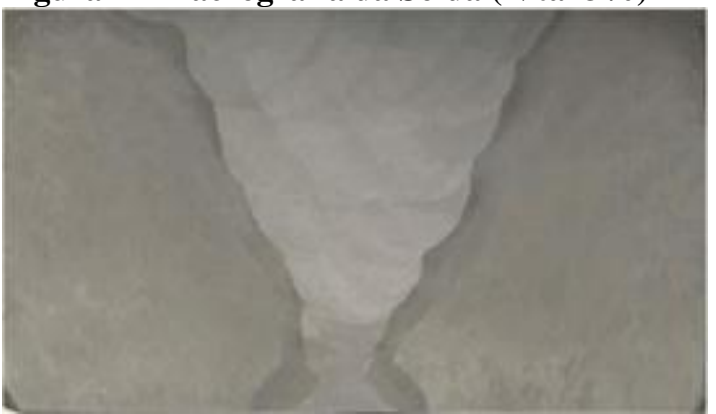

Fonte: os autores (2019)
Figura 2 - Pontos de medição de microdureza

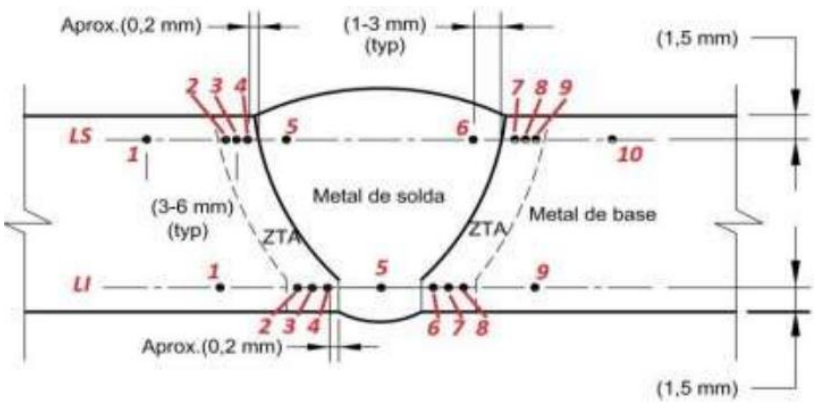

Fonte: os autores (2019)

\section{RESULTADOS E DISCUSSÃO}

Essa seção destina-se a análise e discussão dos resultados da pesquisa.

\subsection{Análises comparativas da resistência à tração}

A Tabela 6 mostra a comparação entre os valores obtidos para os CP 01 e CP 03 nos quais não foram realizados Tratamento Térmico de Alívio de Tensões, enquanto nos CP 02 e CP 04 foram realizados o posterior Tratamento Térmico de alívio de tensões com os valores solicitados pela norma DIN EN 10213 (referência).

Tabela 6 - Análise comparativa Ensaio de Tração

\begin{tabular}{c|c|c|c|c|c}
\hline & $\boldsymbol{\emptyset}(\mathbf{m m})$ & $\begin{array}{c}\text { Área } \\
\left(\mathbf{m m}^{2}\right)\end{array}$ & $\begin{array}{c}\text { Força } \\
\text { máxima (N) }\end{array}$ & $\begin{array}{c}\text { Limite de } \\
\text { Resistência } \\
(\mathbf{M P a})\end{array}$ & $\begin{array}{c}\text { Local da fratura } \\
\text { / Tipo de } \\
\text { fratura }\end{array}$ \\
\hline DIN 10213 & - & - & - & 590 (mín.) & - \\
\hline DIN 10213 & - & - & - & 780 (máx) & - \\
\hline CP 01 & 12,7 & 127,07 & 94646 & 745 & $\begin{array}{c}\text { Metal Base / } \\
\text { Dúctil }\end{array}$ \\
\hline CP 02 & 12,7 & 127,07 & 79085 & 624 & Solda / Dúctil \\
\hline CP 03 & 12,7 & 127,07 & 95162 & 769 & Solda \\
\hline CP 04 & 12,7 & 127,07 & 76758 & 620 & Solda \\
\hline
\end{tabular}

Fonte: os autores (2019)

A Figura 3 mostra a curva de tensão x deformação do CP 03, não submetido ao de Alívio de Tensões. Já a Figura 4, mostra a curva tensão x deformação no qual não foi realizado o referido tratamento térmico (CP 04). 


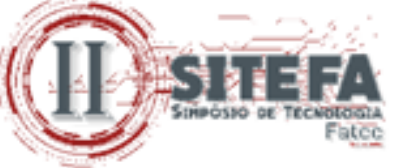

Figura 3 - Curva tensão x deformação CP 03

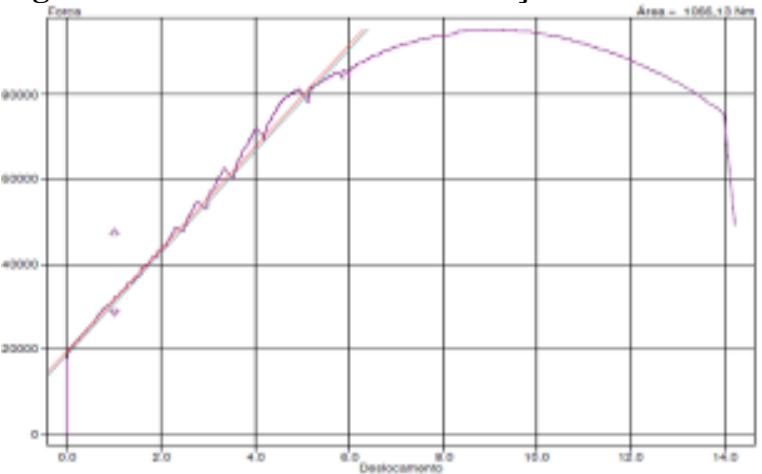

Fonte: os autores (2019)
Figura 4 - Curva tensão x deformação CP 04

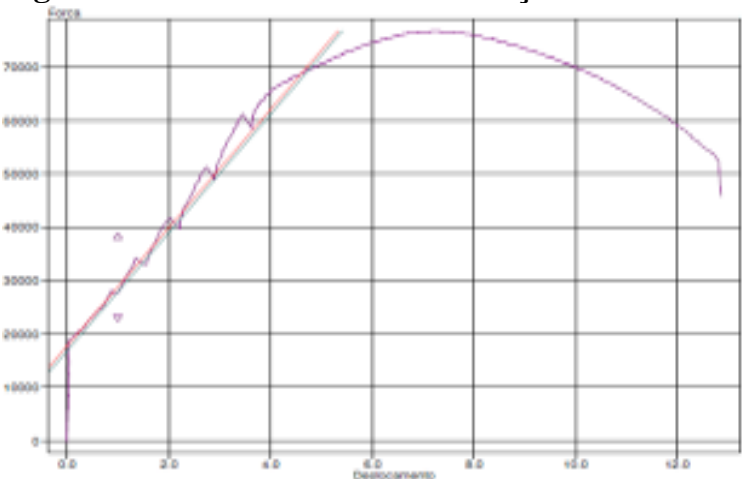

Fonte: os autores (2019)

Pôde-se observar que o rompimento do CP 01, na condição sem alívio de tensões, ocorreu no metal de base conforme Foto 3. Já no CP 02, em que foi realizado o Tratamento Térmico de Alívio de Tensões, a ruptura ocorreu em cima da linha de solda, conforme Foto 4.

Foto 3 - Tração CP 01 sem Alívio de Tensões

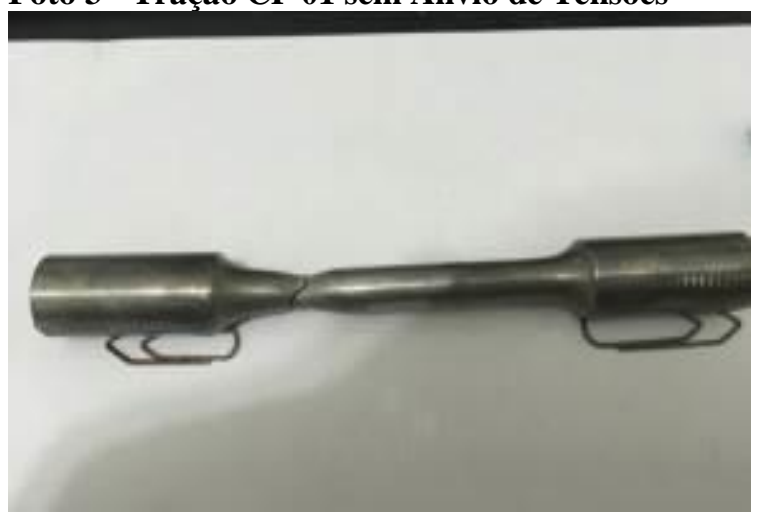

Fonte: os autores (2019)

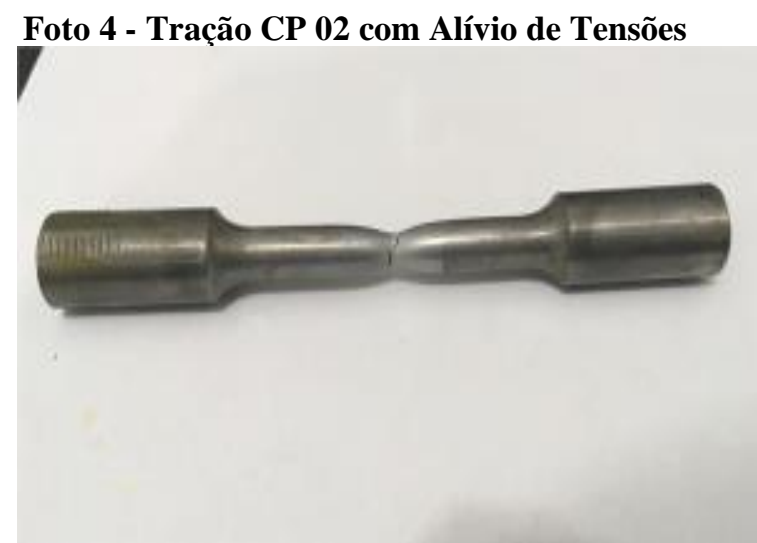

Fonte: os autores (2019)

\subsection{Análises comparativas da resistência a impacto}

A Tabela 7 mostra o resultado obtido a partir do ensaio do CP 01 no qual não foi realizado Tratamento Térmico de Alívio de Tensões após a soldagem, CP 02 em que foi submetido ao referido Tratamento Térmico pós Soldagem e valores solicitados pela norma DIN EN 10213. Ambos os casos foram feitos na temperatura de $20^{\circ} \mathrm{C}$.

Tabela 7 - Análise comparativa Ensaio de Impacto

\begin{tabular}{c|c|c|c|c}
\hline $\begin{array}{c}\text { Condição da } \\
\text { amostra }\end{array}$ & $\begin{array}{c}\text { Resultado dos } \\
\text { Testes (Joules) }\end{array}$ & $\begin{array}{c}\text { Dimensões dos CPs } \\
(\mathbf{m m})\end{array}$ & $\begin{array}{c}\text { Mínimo } \\
\text { especificado }\end{array}$ & $\begin{array}{c}\text { Temperatura } \\
\text { do Ensaio }\end{array}$ \\
\hline $\begin{array}{c}\text { Sem Alívio de } \\
\text { Tensões }\end{array}$ & $\begin{array}{c}\text { CP } 01 \\
40\end{array}$ & $10 \times 10 \times 55$ & $27 \mathrm{~J}$ & $21^{\circ} \mathrm{C}$ \\
\hline $\begin{array}{c}\text { Com Alívio } \\
\text { de Tensões }\end{array}$ & $\begin{array}{c}\mathrm{CP} 02 \\
146\end{array}$ & $10 \times 10 \times 55$ & $27 \mathrm{~J}$ & $21^{\circ} \mathrm{C}$ \\
\hline
\end{tabular}

Fonte: os autores (2019) 


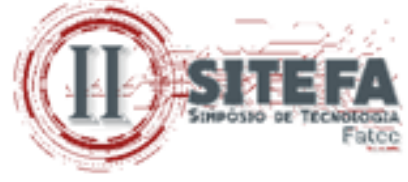

Nas Fotos 5 e 6, podemos verificar o rompimento do CP 01 por fratura do tipo dúctilfrágil, possivelmente pelo fato do material não ter recebido o tratamento térmico de alívio de tensões após o processo de Soldagem. Já o ensaio de impacto referente ao CP 02, observou-se a ocorrência de fratura do tipo dúctil, possivelmente devido ao material ter sido submetido ao tratamento térmico de alívio de tensões após o processo de soldagem.

Foto 5 - Impacto CP 01 sem Alívio de Tensões.

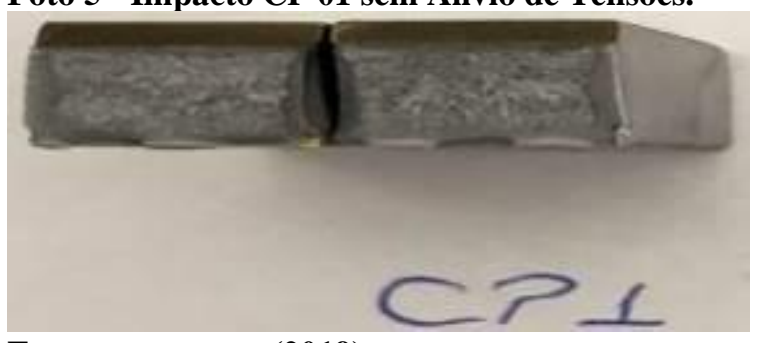

Fonte: os autores (2019)

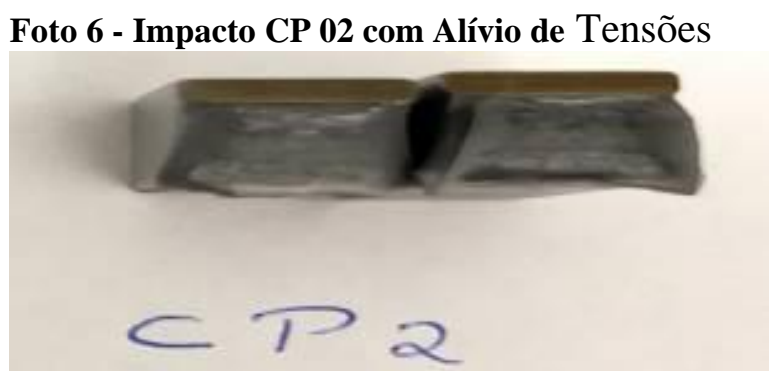

Fonte: os autores (2019)

Tabela 8 - Resultados de microdureza Vickers obtidos nos Corpos de Prova CP1 e CP2

\begin{tabular}{|c|c|c|c|c|c|c|c|c|c|}
\hline \multirow[b]{3}{*}{ Material } & \multirow[b]{3}{*}{$\begin{array}{c}\text { Localização } \\
\text { (Região) }\end{array}$} & \multicolumn{4}{|c|}{ CP 01 - Sem Alívio de Tensões } & \multicolumn{4}{|c|}{ CP 02 - Com Alívio de Tensões } \\
\hline & & \multicolumn{2}{|c|}{ Linha $\mathrm{S}$} & \multicolumn{2}{|c|}{ Linha LI } & \multicolumn{2}{|c|}{ Linha $\mathrm{S}$} & \multicolumn{2}{|c|}{ Linha LI } \\
\hline & & $\begin{array}{c}\text { Pont } \\
\text { o }\end{array}$ & $\begin{array}{c}\text { Resultado } \\
\text { (HV) }\end{array}$ & Ponto & $\begin{array}{l}\text { Resulta } \\
\text { do HV) }\end{array}$ & Ponto & $\begin{array}{c}\text { Resultado } \\
\text { (HV) }\end{array}$ & Ponto & $\begin{array}{c}\text { Resultado } \\
\text { (HV) }\end{array}$ \\
\hline \multirow{4}{*}{$\begin{array}{c}\text { G17CrMoV } \\
5-10\end{array}$} & Metal Base & 1 & 232 & 1 & 244 & 1 & 221 & 1 & 225 \\
\hline & \multirow{3}{*}{ ZTA } & 2 & 466 & 2 & 466 & 2 & 225 & 2 & 246 \\
\hline & & 3 & 441 & 3 & 418 & 3 & 232 & 3 & 244 \\
\hline & & 4 & 473 & 4 & 441 & 4 & 227 & 4 & 251 \\
\hline \multirow{2}{*}{\multicolumn{2}{|c|}{ Metal de Solda }} & 5 & 321 & \multirow{2}{*}{5} & \multirow{2}{*}{306} & 5 & 201 & \multirow{2}{*}{5} & \multirow{2}{*}{205} \\
\hline & & 6 & 313 & & & 6 & 198 & & \\
\hline \multirow{4}{*}{$\begin{array}{c}\text { G17CrMoV } \\
5-10\end{array}$} & \multirow{3}{*}{ ZTA } & 7 & 441 & 6 & 441 & 7 & 244 & 6 & 251 \\
\hline & & 8 & 423 & 7 & 435 & 8 & 232 & 7 & 257 \\
\hline & & 9 & 441 & 8 & 423 & 9 & 251 & 8 & 246 \\
\hline & Metal Base & 10 & 244 & 9 & 254 & 10 & 227 & 9 & 221 \\
\hline
\end{tabular}

Fonte: os autores (2019)

\subsection{Discussões dos resultados obtidos}

No ensaio de tração os corpos de prova denominados CP 01 e CP 03 sem o tratamento de alivio de tensões, o limite de resistência a tração foi de $745 \mathrm{MPa}$ e $769 \mathrm{MPa}$ respectivamente e a ruptura do $\mathrm{CP} 01$ ocorreu no metal de base e do $\mathrm{CP} 03$ ocorreu na região de solda, já os corpos de prova denominados CP 02 e CP 04 submetidos ao tratamento térmico de alivio de tensões, o limite de resistência à tração foi de $624 \mathrm{MPa}$ e $617 \mathrm{MPa}$ respectivamente e a ruptura ocorreu na região de solda.

A análise dos valores obtidos no ensaio de tração e o local da ruptura de ambos os corpos de provas já eram esperados e podem facilmente ser entendidas através dos anexos 1 (certificado de qualidade da chapa fundida) e do anexo 2 (certificado de qualidade do eletrodo revestido). Nestes anexos é demonstrado que o material de base e o eletrodo utilizado possuem propriedades mecânicas e composição química muito similares, portanto a fratura poderia ocorrer em qualquer ponto do corpo de prova. Nos corpos de prova que sofreram o 


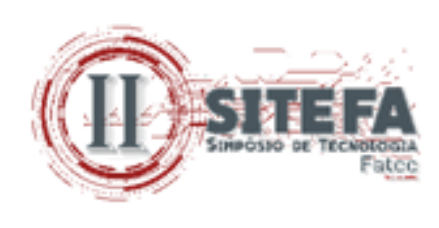

alívio de tensões, a ruptura ocorrida na região da solda é condizente com a diminuição da resistência ao escoamento e ruptura do material na região soldada devido a este tratamento.

As Curvas de Tensão x deformação dos corpos de prova CP 03 e CP 04, apresentaram comportamentos muito similares e ambas demonstram aspecto dúctil. Este fato pode ser explicado devido ao material de base e o material de solda possuírem em suas composições química, baixo teor de carbono, sendo que o material base possui 0,199 \% C e material de solda possui $0,081 \% \mathrm{C}$ e em ambos existem pequenos teores de Cromo

O ensaio de impacto Charpy foi realizado a $21{ }^{\circ} \mathrm{C}$, em ambos os corpos de prova ocorreu ruptura total. O corpo de prova denominado CP 01 sem o tratamento de alívio de tensões absorveu uma energia de 40 Joules, já o corpo de prova denominado CP 02 submetido ao referido tratamento térmico, absorveu uma energia de 146 Joules.

A análise dos valores obtidos no ensaio de impacto demonstra que o corpo de prova CP 02 absorveu por volta de 3,5 vezes mais energia que o corpo de prova CP 01. Estes valores demostram que o tratamento térmico de alívio de tensões melhorou significativamente a ductilidade do material, tornando o corpo de prova mais homogêneo e com propriedades mais uniformes. $\mathrm{O}$ aspecto da superfície de fratura após o ensaio também caracteriza o fato do corpo de prova CP 02 ter absorvido mais energia em comparação com o corpo de prova $\mathrm{CP}$ 01, pois apresenta caráter totalmente dúctil enquanto a superfície de ruptura do CP 01 apresenta característica dúctil-frágil.

No ensaio de dureza Vickers o corpo de prova denominado CP 01 sem o tratamento de alívio de tensões demonstrou resultados de dureza não uniformes entre o metal de base, zona termicamente afetada e a região do metal de solda, com variação de 232 a 473 HV. Já o corpo de prova denominado CP 02 submetido ao tratamento térmico de alívio de tensões, os valores obtidos de dureza demonstraram maior uniformidade ao longo de todo corpo de prova, com a dureza variando entre 205 e $257 \mathrm{HV}$.

A análise dos valores obtidos no ensaio de dureza Vickers mostra que o tratamento térmico de alivio de tensões diminuiu, de forma significante, a dureza na zona termicamente afetada e na região do metal de solda, aumentando a ductilidade nestas regiões do corpo de prova e cumpriu perfeitamente seu papel no sentido de uniformizar as propriedades mecânicas e remover tensões localizadas.

\section{CONCLUSÕES}

Com base nos resultados obtidos, observamos que as amostras submetidas ao tratamento térmico de alivio de tensões, apresentaram melhores resultados tornando o material mais dúctil e homogêneo, mostrando que quando o material a ser aplicado no desenvolvimento de um projeto é o G17CrMoV5.10 o tratamento térmico de alivio de tensões tem grande importância, principalmente quando o material de soldagem é o eletrodo E9018B3 que possui propriedades mecânicas e composição química muito similar a este.

\section{REFERÊNCIAS}

CHIAVERINI, V. Aços e ferros fundidos. ed. Associação Brasileira de metais, 2012.

GARCIA, A.; SPIM, J. A.; SANTOS, C. A. Ensaios dos materiais. 2 ed. Rio de Janeiro: LTC, 2011 
MARQUES, P. V.; MODENESI, P. J.; BRACARENSE, A. Q. Soldagem-Fundamentos e Tecnologia. 4. ed. Elsevier: Rio de Janeiro, 2016.

METRODE WELDINGS CONSUMABLES. Technical Handbook. 2016. Disponível em: https://www.lincolnelectric.com/assets/EU/EN/MetrodeHandbook.pdf. Acesso em: 02 out. 2018.

USIMONTEC. Certificado 23175 da Fundição. 2017

WELDINOX . Certificado 23466. 2017 